\title{
Susceptibility of lamivudine-resistant hepatitis B virus to other reverse transcriptase inhibitors
}

\author{
Suzane Kioko Ono-Nita, ${ }^{1}$ Naoya Kato, ${ }^{1}$ Yasushi Shiratori, ${ }^{1}$ Keng-Hsin Lan, ${ }^{1}$ \\ Hideo Yoshida, ${ }^{1}$ Flair José Carrilho, ${ }^{2}$ and Masao Omata ${ }^{1}$ \\ ${ }^{1}$ Department of Gastroenterology, Faculty of Medicine, University of Tokyo, Tokyo 113-8655, Japan \\ ${ }^{2}$ Department of Gastroenterology, School of Medicine, University of 05403-000 Sao Paulo, Sao Paulo, Brazil
}

Address correspondence to: Naoya Kato, Department of Gastroenterology, Faculty of Medicine, University of Tokyo, 7-3-1 Hongo, Bunkyo-ku, Tokyo 113-8655, Japan. Phone: 81-3-3815-5411, ext. 33070; Fax: 81-3-3814-0021; E-mail: kato-2im@h.u-tokyo.ac.jp.

Received for publication November 23, 1998, and accepted in revised form May 10, 1999.

\begin{abstract}
The emergence of resistant hepatitis B virus (HBV), with mutations in the YMDD motif of the polymerase gene after treatment with lamivudine, is becoming an important clinical problem. In this study, susceptibility of wild-type and lamivudine-resistant HBV M552I, M552V, and L528M/M552V mutants to other reverse transcriptase inhibitors was investigated by transient transfection of full-length HBV DNA into human hepatoma cells. HBV DNA replication was monitored by Southern blot hybridization, which showed the presence of a single-stranded band (representative of the HBV replicative intermediates) in the drug-free, wild-type HBV-transfected cells. This band was diminished in the samples of wild-type HBV DNA treated with either lamivudine, adefovir, or lobucavir. The band intensities from the lamivudine-resistant mutants were not decreased by treatment with lamivudine, but were decreased by the treatments with adefovir or lobucavir. In contrast, penciclovir and nevirapine did not diminish the intensity of the single-stranded band of wild-type HBV or the lamivudine-resistant mutants. These results demonstrate that lamivudine-resistant $\mathrm{HBV}$ is susceptible to adefovir and lobucavir. Lamivudine-resistant HBV should be treated with adefovir or lobucavir, and combination therapy with lamivudine and adefovir/lobucavir may prevent the emergence of lamivudine-resistant HBV.
\end{abstract}

J. Clin. Invest. 103:1635-1640 (1999).

\section{Introduction}

Hepatitis B continues to be a major health problem, accounting for 1.2 million deaths per year worldwide, according to the 1997 World Health Organization (WHO) report (1). Despite the existence of an effective vaccine, there is no completely effective antiviral treatment for patients chronically infected with hepatitis B virus (HBV). The overall response rate to IFN therapy, as measured by hepatitis B e antigen ( $\left.\mathrm{Hb}_{\mathrm{e}} \mathrm{Ag}\right)$ loss, is less than $40 \%$ (2). Because replication of HBV DNA proceeds through reverse transcription (3), the use of reverse transcriptase inhibitors is potentially an attractive option.

Lamivudine (3TC) is a promising reverse transcriptase inhibitor. It is well tolerated, produces a rapid and profound decrease in serum HBV DNA levels in patients with chronic hepatitis B (4), and induces histologic improvement (5). However, in recent clinical trials, $14-39 \%$ of immunocompetent patients developed drug-resistant virus during long-term treatment of hepatitis B (6-8). These lamivudine-resistant viruses contain mutations M552I or M552 V in the Tyr, Met, Asp, Asp motif (YMDD motif) of the polymerase (6-11) considered to be a part of the catalytic center of the reverse transcriptase domain (12).

As a variety of new antiviral agents have been developed, it may be important to evaluate their action on these resistant mutants. Among these drugs, adefovir (PMEA) is a broad-spectrum nucleotide analogue that acts against HIV, herpesviruses, and hepadnaviruses (13-16). Adefovir dipivoxil (the oral prodrug of PMEA) is in clinical trials for use in the treatment of HIV and HBV infection $(15,16)$. It has been shown to be safe, well tolerated, and to reduce serum HBV DNA levels by a median of $4.1 \log _{10}$ and induce seroconversion in $20 \%$ of the 15 patients who were treated for 12 weeks with the drug at $30 \mathrm{mg} /$ day (17).

Lobucavir is a nucleoside analogue with properties similar to ganciclovir that is active against a broad range of herpesvirus and HBV in vitro (18-21). Currently, it is undergoing phase I and phase II clinical trials in the United States to determine both its safety and antiviral activity in adults with chronic hepatitis B (22).

Penciclovir is a potent inhibitor of herpesvirus, varicella-zoster virus, and Epstein-Barr virus (23-25); its antiviral effect on HBV has been demonstrated in vitro and in vivo (24-29). Recently, famciclovir (the oral form of penciclovir) was used as prophylaxis for HBV recurrence and to treat patients with hepatitis $B$ infection after liver transplants (30-33).

Reverse transcriptase can also be inhibited by agents that are not nucleoside or nucleotide analogues. Nevirapine (non-nucleoside reverse transcriptase inhibitor) binds to a hydrophobic pocket in the enzyme-DNA complex near the polymerization active site of HIV reverse transcriptase and blocks the chemical reaction without interfering with nucleotide binding or nucleotideinduced conformational change (34). Nevirapine has been approved for use in combination with nucleoside analogue anti-HIV drugs in HIV-infected patients whose current treatments have failed (35). 
Lamivudine is a promising treatment; however, because a high number of lamivudine-resistant HBV mutants have emerged after long-term administration of the drug, the study of the efficacy of other reverse transcriptase inhibitors against lamivudine-resistant HBV has become imperative. Therefore, we decided to examine the effect of other reverse transcriptase inhibitors on the replication of the lamivudine-resistant HBV, using transient transfection of a full-length HBV DNA in human hepatoma cells.

\section{Methods}

Chemicals. Lamivudine was generously donated by Glaxo Wellcome (Greenford, United Kingdom); adefovir was a gift from Gilead Sciences (Foster City, California, USA); lobucavir was a gift from Bristol-Myers Squibb (Wallingford, Connecticut, USA); nevirapine was a gift from Boehringer Ingelheim (Ridgefield, Connecticut, USA); and penciclovir was a gift from SmithKline Beecham (Worthing, United Kingdom).

Plasmids. HBV DNA was amplified and cloned as described previously (36). Three types of lamivudine-resistant mutants were created by substituting nucleotides to change the codon for Met in the YMDD motif to Ile (M552I mutant) or Val (M552V mutant) and codon 528 for Leu in the B-domain motif to Met (L528M/M552V mutant) (37), using the QuikChange Site-Directed Mutagenesis Kit (Stratagene, La Jolla, California, USA). The polymerase gene of the mutants was sequenced using a cycle DNA sequencing system (Perkin-Elmer Applied Biosystems, Foster City, California, USA), as described previously (38), to confirm the introduction of mutations.

Transfection of full-length $\mathrm{HBV}$ DNA into $\mathrm{HuH-7}$ cells. Fulllength HBV DNA wild-type and lamivudine-resistant mutants were prepared for transfection as previously described (39).

Wild-type

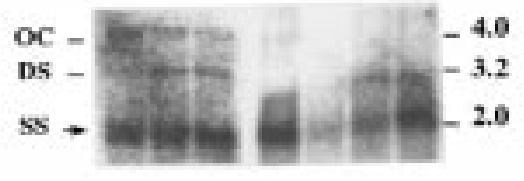

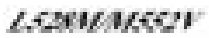

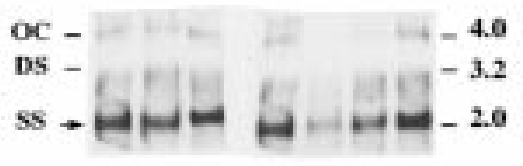

HuH-7 cells (Human Science Research Resource Bank, Osaka, Japan) (40) were cultured in RPMI-1640 supplemented with $0.5 \% \mathrm{FBS}$ and $0.2 \%$ lactalbumin. Approximately $10^{6}$ cells were plated onto a $60-\mathrm{mm}$-diameter dish, and 24 hours later were transfected with $2 \mu \mathrm{g}$ of full-length HBV DNA using Lipofectamine Plus reagent (GIBCO BRL, Gaithersburg, Maryland, USA). Twenty-four hours after transfection, the medium was changed and reincubated with drug-free medium or medium containing several different concentrations of lamivudine, adefovir, lobucavir, nevirapine, or penciclovir, as described previously (41). Medium and cells (rinsed 3 times with icecold PBS) were harvested 3 days later. The efficiency of transfection was monitored by cotransfecting a $\beta$-galactosidase expression plasmid, pCMV $\beta$ (CLONTECH Laboratories Inc., Palo Alto, California, USA). Assays for $\beta$-galactosidase in extracts of HuH-7 cells were performed as described (42). Experiments were performed in triplicate.

Isolation of HBV DNA from transfected cells. Purification of $\mathrm{HBV}$ DNA from intracellular core particles was accomplished using the method described by Günther et al. (39), with a minor modification. Briefly, cells were suspended in $500 \mu \mathrm{L}$ of lysis buffer $(50 \mathrm{mM}$ Tris-HCl [pH 7.4], 1 mM EDTA, and 1\% NP-40), transferred to an Eppendorf tube, vortexed, and allowed to stand on ice for $15 \mathrm{~min}$ utes. Nuclei were pelleted by centrifugation at $4^{\circ} \mathrm{C}, 15,000 \mathrm{~g}$, for 1 minute. The supernatant was transferred to a new tube, adjusted to $10 \mathrm{mM} \mathrm{MgCl}$, and digested with $100 \mu \mathrm{g} / \mathrm{mL}$ of DNase I for 30 minutes at $37^{\circ} \mathrm{C}$. To stop the reaction, EDTA was added to a final concentration of $25 \mathrm{mM}$. Then, $0.5 \mathrm{mg} / \mathrm{mL}$ proteinase $\mathrm{K}$ and $1 \%$ SDS were added and incubated at $0^{\circ} \mathrm{C}$ for 4 hours. Phenol-chloroform (1:1) extraction was performed, and the nucleic acids were ethanol precipitated along with a glycogen carrier.

Southern blot bybridization of HBV DNA. HBV DNA was resolved in $1.5 \%$ agarose gel, transferred to a nylon membrane (Hybond $\mathrm{N}+$; Amersham International, Little Chalfont, United Kingdom) by Southern blotting, and hybridized with a ${ }^{32} \mathrm{P}-$-labeled wild-type, full-length HBV DNA probe generated with Ready-To-Go DNA labeling kit (-dCTP) (Pharmacia Biotech AB, Uppsala, Sweden). Autoradiography was performed and analyzed by using a BAS 2000 image analyzer (Fuji Photo Film, Tokyo, Japan).

Effect of antiviral drugs on the replication of wild-type or mutant $H B V$. To compare the effect of the antiviral drugs on wild-type and lamivudine-resistant mutants of HBV, we transfected HuH-7 cells with HBV DNA and added the antiviral drugs at a concentration of $8.7 \mu \mathrm{M}$. We chose this concentration because it was previously demonstrated to be the $\mathrm{IC}_{90}$ for lamivudine of the wild-type HBV (41) and would allow direct comparison with the other drugs. We also applied several concentrations of the antiviral drugs to calculate their $\mathrm{IC}_{50}$, to standardize the assay, and to view the of an inhibition curve. To evaluate the susceptibility of HBV to lamivudine, lobucavir, adefovir, penciclovir, and nevirapine, Southern blot hybridization on DNA extracts from transfected cells was performed. We selected these drugs because the first 4 are already in ongoing clinical trials for hepatitis $B(8,16,22,33)$, and chose nevirapine because it is a reverse transcriptase inhibitor. The single-stranded HBV DNA band, previously shown to represent HBV intermediates $(39,43)$, was analyzed to assess the efficacy of the reverse transcriptase inhibitors on HBV replication. This band was quantified and normalized for transfection efficiency based on $\beta$-galactosidase activity.

\section{Results}

Wild-type HBV is susceptible to lamiundine, lobucavir, and adefovir. Southern blot hybridization on DNA extracts showed the presence of a single-stranded band (representative of the HBV replicative intermediates) in the 
Figure 2

Diagram comparing the mean \pm SD susceptibility of wild-type, M552I, M552V, and L528M/M552V mutants of HBV transfected into $\mathrm{HuH}-7$ cells to lamivudine, lobucavir, adefovir, penciclovir, and nevirapine at a concentration of $8.7 \mu \mathrm{M}$. Single-stranded bands were quantified using a BAS 2000 image analyzer and normalized for transfection efficiency based on $\beta$-galactosidase activity. The single-stranded band of control was calculated as 100 .
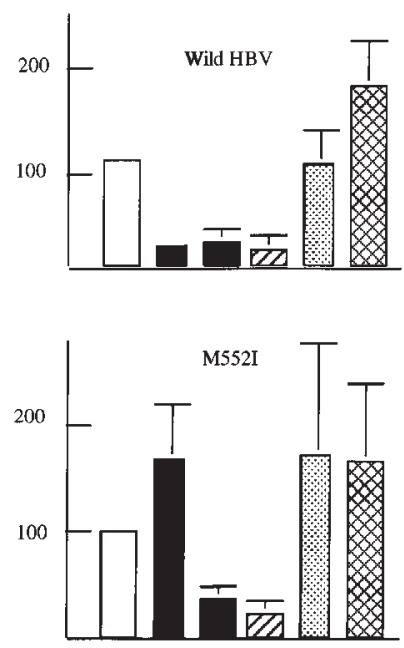

Nevirapine
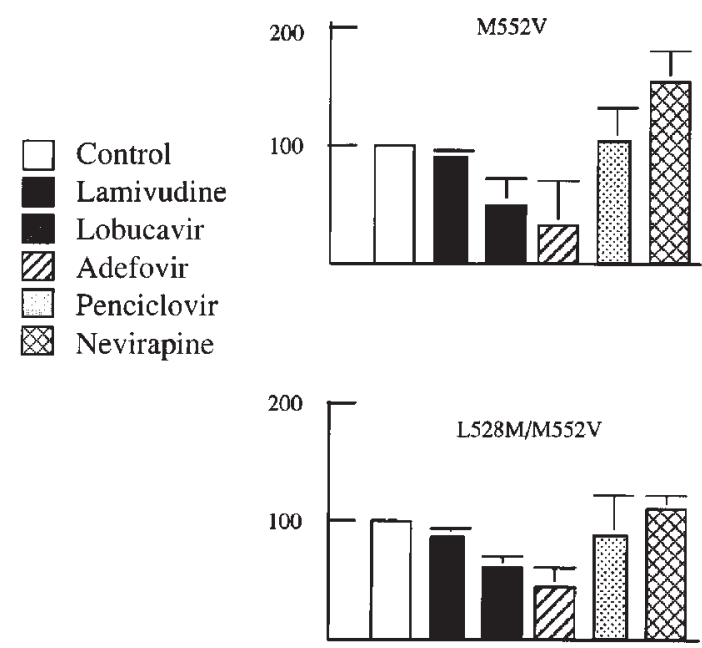

drug-free samples (Figure 1, lane a). This band was diminished by $83.3 \pm 2.2 \%, 87.2 \pm 14.5 \%$, and $79.7 \pm$ $12.6 \%$ (Figure 2) in the samples transfected with wildtype HBV DNA that was treated with lamivudine (Figure 1, lane b), adefovir (Figure 1, lane d), or lobucavir (Figure 1 , lane e), respectively. Inhibition curves for each drug are provided in Figure 3, and calculated antiviral $\mathrm{IC}_{50}$ values are presented in Table 1.

Lamivudine-resistant $H B V$ is susceptible to lobucavir and adefovir. To evaluate the susceptibility of lamivudineresistant mutants of $\mathrm{HBV}$ to adefovir, lobucavir, penciclovir, and nevirapine, Southern blot hybridizations on DNA extracts from transfected cells were performed (Figure 1). Southern blot hybridization on DNA extracts showed the presence of a single-stranded band (representative of the HBV replicative intermediates) in the drug-free samples (Figure 1, lane a). When treated with lamivudine, the M552I, M552V, and L528M/M552V mutants' band intensities were not decreased, thus confirming their lamivudine-resistant phenotype. However, following treatment of the mutants with adefovir and lobucavir, the band intensities were decreased by $79.3 \pm 12.6 \%$ and $64.1 \pm 11.5 \%$ for the M552I mutant; by $69.2 \pm 37.5 \%$ and $51.7 \pm$ $21.7 \%$ for the $M 552 \mathrm{~V}$ mutant; and by $57.0 \pm 9.9 \%$ and $41.0 \pm 14.8 \%$ for the $L 528 M / M 552 \mathrm{~V}$ mutant, respectively (Figure 2 ). In contrast, penciclovir and nevirapine did not diminish the band intensities of the lamivudine-resistant mutants.

We determined the inhibition of HBV DNA synthesis using several concentrations of the drugs. Inhibition curves for each drug showed that the properties of inhibition were sigmoidal (Figure 3 ). The antiviral drugs' IC $_{50}$ values are presented in Table 1 . It is interesting to note that whereas the wild-type $\mathrm{HBV}$ has an $\mathrm{IC}_{50}$ for adefovir and lobucavir lower than $1 \mu \mathrm{M}$, the lamivudine-resistant variants showed a higher $\mathrm{IC}_{50}$, ranging from 2.2 to $7 \mu \mathrm{M}$.

Lack of susceptibility of $H B V$ to penciclovir and nevirapine. The single-stranded band in the samples of wild-type and lamivudine-resistant HBV treated with penciclovir was not decreased as expected (Figure 1, lane f). To evaluate whether a higher dose of penciclovir would inhibit wild-type HBV replication in this sys- tem, HuH-7 cells transiently transfected with wildtype HBV DNA were treated with increasing doses of penciclovir $(0-80 \mu \mathrm{M})$ and lamivudine $(0-10 \mu \mathrm{M})$. While lamivudine clearly inhibited the replication of wild-type HBV, the replication of wild-type HBV was not diminished by even higher doses of penciclovir (Figures 4 and 5). The sequence of wild-type HBV DNA was checked for mutations within the B domain of the polymerase gene and associated with reduced penciclovir sensitivity as described previously (32). The sequence of the HBV DNA used in this study did not contain the described mutations (data not shown). Nevirapine also did not diminish the replication of wild-type HBV or the lamivudine-resistant mutants (Figure 1, lane c; and Figure 5). Because penciclovir and nevirapine did not inhibit replication of wild-type HBV, we did not estimate the dose-dependency curve for the lamivudine-resistant HBV.

\section{Discussion}

Hepatitis B continues to be a life-threatening disease worldwide (1), and IFN- $\alpha$ - the only approved treatment - has dose-limiting side effects and limited benefit (2). Thus, more effective and safer treatments for hepatitis B are urgently required. Currently, lamivudine is a promising treatment for chronic hepatitis B and is in widespread use. However, resistance to lamivudine has been observed in both immunocompetent patients and in patients after liver transplants, and is associated with a mutation Met to Ile or Val in

Table 1

Susceptibility of HBV constructs to reverse transcriptase inhibitors

\begin{tabular}{lcccc}
\hline & \multicolumn{4}{c}{ IC50 $(\mu \mathrm{M})^{\mathrm{A}}$} \\
\cline { 2 - 5 } Antiviral & Wild-type & M552I & M552V & L528M/M552V \\
Lamivudine & $<1$ & $>80$ & 33 & $>80$ \\
Adefovir & $<1$ & 4.5 & 4.9 & 2.2 \\
Lobucavir & $<1$ & 5.0 & 3.6 & 7.0 \\
Penciclovir & $>80$ & ND & ND & ND \\
Nevirapine & $>80$ & ND & ND & ND \\
\hline
\end{tabular}

AIC50 values represent the mean of 3 experiments. ND, not done. 
the YMDD motif of the HBV polymerase gene (7-10). In addition, a mutation from Leu to Met has been described in the $\mathrm{B}$ domain of the polymerase gene associated with the M552V mutant (37). Because reverse transcriptase has a fundamental role in the replication of retroviruses and $\mathrm{HBV}$, it became an attractive target in chemotherapy for these viruses. Reverse transcriptase inhibitors can be broadly classified into 2 groups: nucleoside (or nucleotide) analogues (lamivudine, adefovir, lobucavir, and penciclovir) that are active in the triphosphate form; and non-nucleoside reverse transcriptase inhibitors (NNRTIs) (nevirapine) that interact directly with reverse transcriptase. Therefore, we decided to study the effect of 3 antiviral agents (adefovir, lobucavir, and penciclovir) currently used in clinical trials and to study the effect of nevirapine on lamivudine-resistant HBV, using transient transfection of a full-length HBV DNA in human hepatoma cells.

a

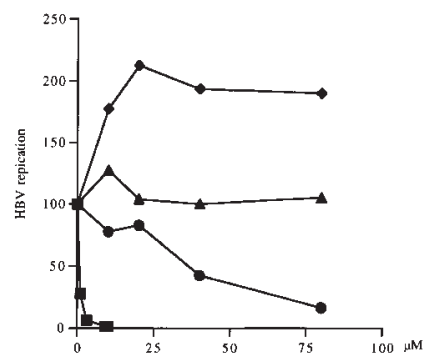

b

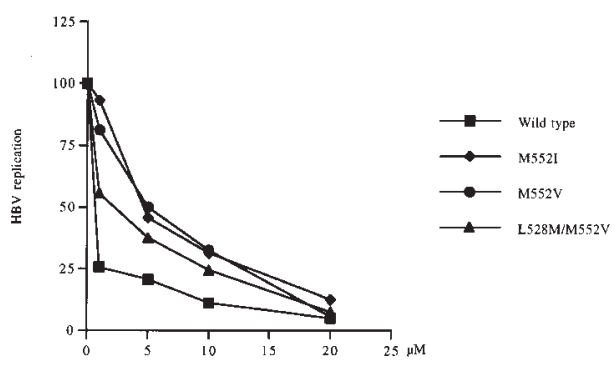

C

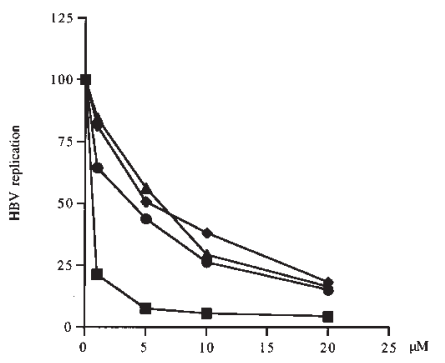

\section{Figure 3}

Drug inhibition curves of wild-type and lamivudine-resistant HBV transfected into $\mathrm{HuH}-7$ cells treated with indicated concentrations of lamivudine (a), adefovir (b), and lobucavir (c). Values represent the mean of 3 experiments.
The HepG2.2.15 cell line has been used to evaluate the effect of antiviral drugs against $\operatorname{HBV}(26-28,44)$. However, this system does not permit analysis of HBV mutants that are now being reported, because these cells are stably transfected with wild-type HBV. Using the system of transient transfection of a full-length HBV DNA into HuH-7 cells, we were able to evaluate other potential therapeutic agents that might improve the treatment of chronic hepatitis $B$.

To test the replication ability of the wild-type and lamivudine-resistant mutant HBV, Southern blot hybridization on DNA extracts was performed because it is an established method to monitor the antiviral activity of drugs for HBV (26-28, 44-47). As was reported previously $(39,43)$, open circular, double-stranded, and single-stranded HBV DNA bands were seen at 4.0 $\mathrm{kbp}, 3.2 \mathrm{kbp}$, and $2.0 \mathrm{kbp}$, respectively. The singlestranded HBV DNA band, previously shown to represent HBV replicative intermediates (3), was analyzed to study the function of inhibitors of reverse transcriptase by inhibiting the conversion of the pregenomic RNA to single-stranded DNA. The effects of the antiviral drugs were determined by the addition of a drug 24 hours after transfection in order to avoid interference of these drugs in the transfection step. This system may be a valid way to evaluate the effects of antiviral agents on $\mathrm{HBV}$ replication, because the formation of singlestranded DNA occurred 72 hours after transfection (data not shown). Because the levels of $\mathrm{HB}_{\mathrm{s}} \mathrm{Ag}$ did not change in the samples treated in this system, $\mathrm{HB}_{\mathrm{s}} \mathrm{Ag}$ expression could not be used to evaluate antiviral efficacy. This lack of change could be explained by the drugs' mechanisms of action, which inhibit only the reverse transcription step and cannot inhibit transcription and translation of transfected HBV DNA.

Clinical studies have shown that adefovir is safe, well tolerated $(15,16)$, and reduces serum HBV DNA levels by more than $4 \log _{10}(99.99 \%)$ (17). The results presented here confirm the in vitro anti-hepadnaviral activity of adefovir. Following administration of adefovir, the single-stranded band of wild-type HBV DNA was significantly diminished (Figure 1). This result is in agreement with the results of Yokota et al. (45) and Heijtink et al. (46), indicating an inhibitory effect of adefovir in human and duck HBV in vitro infection.

Our study demonstrates that lobucavir could decrease replication of wild-type $\mathrm{HBV}$ in vitro, and this result is in accordance with other studies that show that lobucavir has in vitro and in vivo activity against $\operatorname{HBV}(20,21,47)$. Currently, clinical trials are underway to determine its safety and its antiviral activity against $\mathrm{HBV}$ and cytomegalovirus $(20,22)$.

In contrast to the significant inhibitory effect of lamivudine on wild-type $\mathrm{HBV}$, the resistant mutants M552I, M552V, and L528M/M552V did not show significant decrease in replication, even with higher doses of lamivudine (Figure 3a). In the present study, we demonstrate that adefovir and lobucavir markedly reduce viral DNA production by the lamivudine-resistant mutants. However, even though adefovir and lobucavir are effective against lamivudine-resistant $\mathrm{HBV}$, the dose used to inhibit replication of the wild-type virus is not enough 


\section{Figure 4}

Southern blotting hybridization analysis of HBV transfected into $\mathrm{HuH}-7$ cells treated with lamivudine and penciclovir. Lanes correspond to DNA extracted from viral core particles derived from $\mathrm{HuH}-7$ cells. The arrow indicates the single-stranded band, representative of HBV replication intermediates. OC, open circular; DS, double-stranded; SS, single-stranded.
Lamivudine

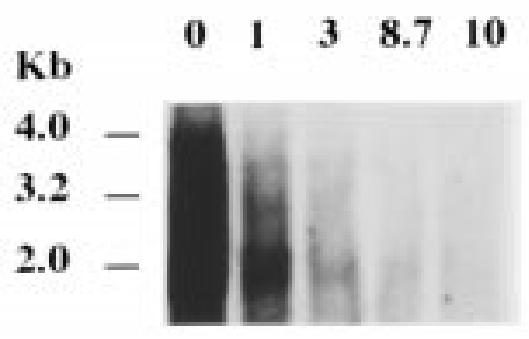

Penciclovir

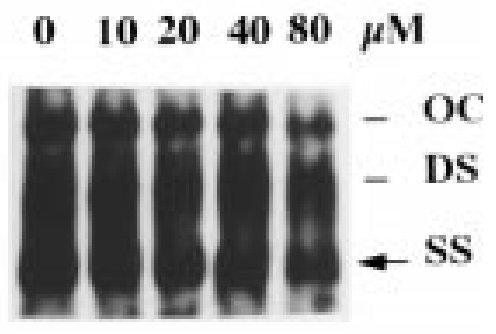

to completely inhibit the lamivudine-resistant mutants. This result suggests not only that mutations associated with lamivudine resistance resulted in a small decrease in susceptibility to adefovir and lobucavir, but also indicates that higher doses of the drugs may be required to achieve complete suppression of viral replication. Also, it is interesting to note that this decrease in susceptibility to lamivudine and lobucavir is progressive among the mutants, where the $M 552 \mathrm{~V}$ mutant is more susceptible than the $L 528 \mathrm{M} / \mathrm{M} 552 \mathrm{~V}$ mutant. Allen et al. (37) had shown previously that in the double mutant $(L 528 M / M 552 \mathrm{~V})$, each mutation may contribute partially to the loss of sensitivity to lamivudine in vitro. Our study suggests that the same loss of sensitivity can occur for lobucavir but not for adefovir.

Although mutations in HIV reverse transcriptase associated with decreased susceptibility to adefovir were described in vitro (48), these mutations have been rarely observed in vivo and were not associated with rebound viremia (48); to date there has been no description of mutations in the HBV reverse transcriptase leading to adefovir resistance. Interestingly, these mutations in the HIV reverse transcriptase are not located in any of the 5 conserved motifs of RNAdependent polymerases of HIV.

Unexpectedly, penciclovir did not show any antiviral effects against HBV wild-type or lamivudine-resistant mutants in our study, despite previous evidence of a capacity to inhibit replication of HBV in vitro and in vivo (23-29). The sequence was confirmed to be wildtype $\mathrm{HBV}$ in the B domain of polymerase because mutations that confer resistance to penciclovir have been described previously in this region (32). Stably transfected cells, HepG2.2.15, were also used to check the susceptibility to penciclovir (data not shown). This experiment confirmed the results obtained using $\mathrm{HuH}$ 7 cells, showing that up to $80 \mu \mathrm{M}$ of penciclovir did not diminish the production of replicative intermediates in either cell line, and is in agreement with another study that found an $\mathrm{EC}_{50}$ of $100 \mu \mathrm{M}$ for penciclovir (21). A previous report showed that penciclovir could diminish the production of the covalently closed circular (CCC) DNA form of duck $\mathrm{HBV}$, an event that occurs prior to transcription and reverse transcription (27). These conflicting results may suggest the possibility that penciclovir could inhibit HBV replication by blocking a step (other than reverse transcription) that is not detected in our assay, which monitors only the formation of the single-stranded DNA intermediate band.
Nevirapine is the first NNRTI to be approved for the treatment for HIV (35). Because it inhibits replication by blocking reverse transcription (34), we attempted to evaluate whether it could inhibit the replication of HBV. Like other NNRTIs, nevirapine is a potent inhibitor of HIV reverse transcriptase, but the spectrum of activity is extremely narrow because it is not effective against other retroviruses. Our results may confirm that nevirapine might be specific for HIV.

Given the high incidence of lamivudine-resistant $\mathrm{HBV}$, monotherapy with lamivudine for $\mathrm{HBV}$ is unlikely to be sufficient to eradicate it $(49,50)$. A more efficient strategy to prevent the emergence of a resistant virus should be a goal in the treatment of chronic hepatitis B (51). The combination of lamivudine with adefovir or lobucavir could be expected to be one approach to preventing the emergence of lamivudine resistance, because lamivudine-resistant mutants are susceptible to both adefovir and lobucavir.

\section{Acknowledgments}

This study was supported by a Research Grant for Immunology, Allergy and Organ Transplant from the Ministry of Health and Welfare, Japan. We are also grateful to our many colleagues for their helpful discussions during the course of this study. The authors wish to thank Boehringer Ingelheim for donation of nevirapine, Bristol-Myers Squibb for donation

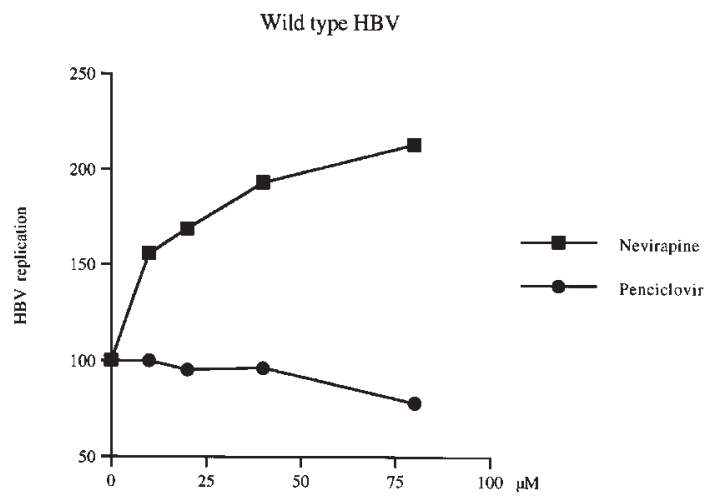

Figure 5

Lack of susceptibility of HBV to penciclovir and nevirapine. Drug inhibition curves of wild-type HBV transfected into $\mathrm{HuH}-7$ cells treated with indicated concentrations of penciclovir and nevirapine. Values represent the mean of 3 experiments. 
of lobucavir, Gilead Sciences for donation of adefovir, Glaxo Wellcome for donation of lamivudine, and SmithKline Beecham for donation of penciclovir. We thank Mitsuko Tsubouchi for technical assistance.

1. World Health Organization warns of growing "crisis of suffering." 1997. http://www.who.ch/whr/1997/presse.htm.

2. Wong, D.K.H., et al. 1993. Effect of alpha-interferon treatment in patients with hepatitis B antigen-positive chronic hepatitis B. A metaanalysis. Ann. Intern. Med. 119:312-323.

3. Summers, J., and Mason, W.S. 1982. Replication of the genome of a hepatitis B-like virus by reverse transcription of an RNA intermediate. Cell. 29:403-415.

4. Dienstag, J.L., et al. 1995. A preliminary trial of lamivudine for chronic hepatitis B virus infection. N. Engl. J. Med. 333:1657-1661.

5. Honkoop, P., de Man, R.A., Zondervan, P.E., and Schalm, S.W. 1997. Histological improvement in patients with chronic hepatitis B virus infection treated with lamivudine. Liver. 17:103-106.

6. Lai, C.L., et al. 1997. Genotypic resistance to lamivudine in a prospective placebo-controlled multicenter study in Asia of lamivudine therapy for chronic hepatitis B infection: incidence kinetics of emergence and correlation with disease parameters. Hepatology. 26:259A. (Abstr.)

7. Honkoop, P., Niesters, H.G.M., de Man, R.A.M., Osterhaus, A.D.M.E., and Schalm S.W. 1997. Lamivudine resistance in immunocompetent chronic hepatitis B. J. Hepatol. 26:1393-1395.

8. Lai, C.L., et al. 1998. A one-year trial of lamivudine for chronic hepatitis B. N. Engl. J. Med. 339:61-68.

9. Tipples, G.A., et al. 1996. Mutation in HBV RNA-dependent DNA polymerase confers resistance to lamivudine in vivo. Hepatology. 24:714-717.

10. Bartholomew, M.M., et al. 1997. Hepatitis-B-virus resistance to lamivudine given for recurrent infection after orthotopic liver transplantation. Lancet. 349:20-22.

11. Ling, R., et al. 1996. Selection of mutations in the hepatitis B virus polymerase during therapy of transplant recipients with lamivudine. Нераtology. 24:711-713.

12. Kamer, G., and Argos, P. 1984. Primary structural comparison of RNAdependent polymerases from plant, animal and bacterial viruses. Nucleic Acids Res. 12:7269-7282

13. De Castro, L.M., et al. 1991. Phosphonylmethoxyalkyl purine and pyrimidine derivatives for treatment of opportunistic cytomegalovirus and herpes simplex virus infections in murine AIDS. Antiviral Res. 16:101-114.

14. Balzarini, J., et al. 1989. Marked in vivo antiretrovirus activity of 9-(2phosphonylmethoxyethyl)adenine, a selective anti-human immunodeficiency virus agent. Proc. Natl. Acad. Sci. USA. 86:332-336.

15. Deeks, S.G., et al. 1997. The safety and efficacy of adefovir-dipivoxil, a novel anti-human immunodeficiency virus (HIV) therapy, in HIV-infected adults: a randomized, double-blind, placebo-controlled trial. J. Infect. Dis. 176:1517-1523.

16. Gilson, R.J.C., et al. 1996. A placebo-controlled phase I/II study of adefovir dipovoxil (bis-POM PMEA) in patients with chronic hepatitis B infection. Hepatology. 24:281A. (Abstr.)

17. Jeffers, L., et al. 1998. A phase II dose-ranging, placebo-controled trial of adefovir dipivoxil for the treatment of chronic hepatitis B virus infection. Antiviral Res. 37:A197. (Abstr.)

18. Terry, B.J., Cianci, C.W., and Hagen, M.E. 1991. Inhibition of herpes simplex virus type I DNA polymerase by $[1 \mathrm{R}(1 \alpha, 2 \beta, 3 \alpha)]-9-[2,3-\mathrm{Bis}$ (hydroxymethyl)cyclobutyl] guanine. Mol. Pharmacol. 40:591-596.

19. Yang, H., Drain, R.L., Franco, C.A., and Clark, J.M. 1996. Efficacy of BMS-180194 against experimental cytomegalovirus infections in immunocompromised mice. Antiviral Res. 26:1-9.

20. Flaherty, J.F., Jr. 1996. Current and experimental therapeutic options for cytomegalovirus disease. Am. J. Health Syst. Pharm. 53(Suppl. 2):S4-S11.

21. Innaimo, S.F., et al. 1997. Identification of BMS-200475 as a potent and selective inhibitor of hepatitis B virus. Antimicrob. Agents Chemother. 41:1444-1448.

22. Bloomer, J., Chan, R., Sherman, M., and Ingraham, P. 1997. Phase $1 / 2$ study of oral Lobucavir in adults with chronic hepatitis B infection. In Program and abstracts of the Second International Conference on Therapies for Viral Hepatitis. Kona, HI. 23. (Abstr.)

23. Boyd, M.R., Safrin, S., and Kern, E.R. 1993. Penciclovir: a review of its spectrum of activity, selectivity and cross-resistance pattern. Antiviral Chem. Chemother. 4(Suppl. 1):3-11.

24. Bacon, T.H. 1996. Famciclovir, from the bench to the patient: a comprehensive review of preclinical data. Int. J. Antimicrob. Agents. 7:119-134.

25. Shaw, T., Mok, S.S., and Locarnini, S.A. 1996. Inhibition of hepatitis B virus DNA polymerase by enantiomers of penciclovir triphosphate and metabolic basis for selective inhibition of HBV replication by penciclovir. Hepatology. 24:996-1002.
26. Korba, B.E., and Boyd, M.R. 1996. Penciclovir is a selective inhibitor of hepatitis B virus replication in cultured human hepatoblastoma cells. Antimicrob. Agents Chemother. 40:1282-1284.

27. Colledge, D., Locarnini, S., and Shaw, T. 1997. Synergistic inhibition of hepadnaviral replication by lamivudine in combination with penciclovir in vitro. Hepatology. 26:216-225.

28. Korba, B.E. 1995. In vitro evaluation of combination therapies against hepatitis B virus replication. Antiviral Res. 29:49-51.

29. Lin, E., Luscombe, C., Colledge, D., Wang, Y.Y., and Locarnini, S. 1998. Long-term therapy with the guanine nucleoside analog penciclovir controls chronic duck hepatitis B virus infection in vivo. Antimicrob. Agents Chemother. 42:2132-2137.

30. Böker, K.H.W., Ringe, B., Krüger, M., Pichmayr, R., and Manss MP. 1994. Prostaglandin E plus famciclovir: a new concept for the treatment of severe hepatitis B after liver transplantation. Transplantation. 54:1706-1708.

31. Klein, M., et al. 1997. Conversion of recurrent delta-positive hepatitis B infection to seronegativity with famciclovir after liver transplantation. Transplantation. 64:162-163.

32. Aye, T.T., et al. 1997. Hepatitis B polymerase mutations during antiviral therapy in a patient following liver transplantation. J. Hepatol. 26:1148-1153.

33. Singh, N., Gayowski, T., Wannstedt, C.F., Wagener, M.M., and Marino, I.R. 1997. Pretransplant famciclovir as prophylaxis for hepatitis B virus recurrence after liver transplantation. Transplantation. 63:1415-1419.

34. Spence, R.A., Kati, W.M., Anderson, K.S., and Johnson, A.K. 1995. Mechanism of inhibition of HIV-1 reverse transcriptase by nonnucleoside inhibitors. Science. 267:988-993.

35. Kupec, I.F. 1996. FDA approves nevirapine to treat HIV. http://www.fda.gov/bbs/topics/ANSWERS/ANS00742.html.

36. Ono-Nita, S.K., et al. 1999. YMDD motif in hepatitis B virus DNA polymerase influences on replication and lamivudine resistance: a study by in vitro full-length viral DNA transfection. Hepatology. 29:939-945.

37. Allen, M.I., et al. 1998. Identification and characterization of mutations in hepatitis B virus resistant to lamivudine. Hepatology. 27:1670-1677.

38. Togo, G., et al. 1996. A transforming growth factor b type II receptor gene mutation common in sporadic cecum cancer with microsatellite instability. Cancer Res. 56:5620-5623.

39. Günther, S., et al. 1995. A novel method for efficient amplification of whole hepatitis B virus genomes permits rapid functional analysis and reveals deletion mutants in immunosuppressed patients. J. Virol. 69:5437-5444.

40. Nakabayashi, H., Taketa, K., Miyano, K., Yamane, T., and Sato J. 1982. Growth of human hepatoma cell lines with differentiated functions in chemically defined medium. Cancer Res. 42:3858-3863.

41. Fischer, K.P., and Tyrrel, D.L.J. 1996. Generation of duck hepatitis B virus polymerase mutants through site-directed mutagenesis which demonstrate resistance to lamivudine $\left[(-)-\beta \mathrm{L}-2^{\prime}, 3^{\prime}\right.$-dideoxi-3'-thiacytidine] in vitro. Antimicrob. Agents Chemother. 40:1957-1960.

42. Sambrook, J., Fritsch, E.F., and Maniatis, T. 1989. Molecular cloning: a laboratory manual. Cold Spring Harbor Laboratory Press. Cold Spring Harbor, NY. 16.56-16.67.

43. Yokosuka O., Omata, M., Imazeki, F., Okuda, K., and Summers, J. 1985. Changes of hepatitis B virus DNA in liver and serum caused by recombinant leukocyte interferon treatment: analysis of intrahepatic replicative hepatitis B virus DNA. Hepatology. 5:728-734.

44. Korba, B.E., and Gerin, J.L. 1992. Use of a standardized cell culture assay to assess activities of nucleoside analogs against hepatitis B virus repliation. Antiviral Res. 19:55-70.

45. Yokota, T., et al. 1991. Inhibitory effects of selected antiviral compounds on human hepatitis B virus DNA synthesis. Antimicrob. Agents Chemother. 35:394-397.

46. Heitjink, R.A., et al. 1993. Inhibitory effect of 9-(phosphonylmethoxyethyl)-adenine (PMEA) on human and duck hepatitis B virus infection. Antiviral Res. 21:141-153.

47. DeHertogh, D., Collono, R., and Grasela, D. 1997. Lobucavir and BMS200475: two potent new agents for hepatitis B. In Program and abstracts of the Second International Conference on Therapies for Viral Hepatitis. Kona, HI. 1. (Abstr.)

48. Cherrington, J.M., Mulato, A.S., Fuller, M.D., and Chen, M.S. 1996. Novel mutation (K70E) in human immunodeficiency virus type 1 reverse transcriptase confers decreased susceptibility to 9-[2-(phosphonomethoxyl)ethyl]adenine in vitro. Antimicrob. Agents Chemother. 40:2212-2216.

49. Lau, G.K., et al. 1999. Treatment of chronic hepatitis B virus infection: an Asian-Pacific perspective. J. Gastroenterol. Hepatol. 14:3-12.

50. Hong, J.H., Choi, Y., Chun, B.K., Lee, K., and Chu, C.K. 1998. Current status of anti-HBV chemotherapy. Arch. Pharm. Res. 21:89-105.

51. Omata, M. 1998. Treatment of chronic hepatitis B infection. N. Engl. J. Med. 339:114-115. 